\title{
Reparations and Egalitarianism
}

\author{
Megan Blomfield ${ }^{1}$
}

Accepted: 26 May 2021/ Published online: 5 June 2021

(C) The Author(s) 2021

\begin{abstract}
Some claim that a commitment to egalitarianism is in tension with support for reparations for historical injustice. This tension appears to arise insofar as egalitarianism is a forwardlooking approach to justice: an approach that tells us what kind of world we should aim to build, where that world is not defined in terms of the decisions or actions of previous generations. Some have claimed that egalitarianism thereby renders reparations redundant (what I will refer to as the redundancy thesis). One popular option for egalitarians who aim to reject this thesis is to insist that historical injustices demand reparations when they have caused present-day inequality (the causal approach). A promising alternative, skilfully defended by Alasia Nuti in Injustice and the Reproduction of History, is to argue that historical injustices stand in need of repair when they are reproduced into the present-day, such that some past and present injustices are in fact the same injustice. In this paper, I assess these egalitarian responses to the redundancy thesis. I find that Nuti's account is equipped to reject this thesis, but that the same lines of reply can be adopted by proponents of the causal approach. I suggest that both approaches therefore be viewed as potential ways to conceptualise the relationship between historical injustice and our present normative circumstances; and that in choosing between them, we should understand ourselves to be engaged in an ameliorative project - a project that is guided by, and designed to help us to achieve, our legitimate purposes.
\end{abstract}

Keywords Reparations · Egalitarianism · Historical injustice $\cdot$ Redress $\cdot$ Structural injustice $\cdot$ Ameliorative analysis

\section{Introduction}

The British Slave Abolition Act of 1833, which came into force in August 1834, formally abolished slavery in Britain's Caribbean, Mauritius, and Cape colonies. This in no way constituted a clean break from Britain's centuries of involvement with Transatlantic slavery.

Megan Blomfield

m.blomfield@sheffield.ac.uk

1 Department of Philosophy, University of Sheffield, Sheffield, UK 
For one thing, the act did not apply to other parts of the British Empire, such as 'Ceylon' (now Sri Lanka) and British India. For another, the formal emancipation granted by this Act did not come with any reparation for those who had been enslaved, many of whom entered a technically different form of unfree labour under the 'apprenticeship' system. Slave owners on the other hand - including many 'absentee' owners living in Britain - were compensated for their losses to the tune of $£ 20$ million. This was a huge amount of money, equivalent to about $40 \%$ of the government's yearly expenditure at the time. The loan taken out to cover this compensation was only settled by British taxpayers in 2015 . $^{1}$

Are reparations owed for British involvement in Transatlantic slavery? This question concerns how people in the present ought to respond to historical injustice. I will define a historical injustice, roughly speaking, as an injustice for which those who were originally responsible, and those who were originally wronged, are no longer alive. I will use the term 'reparative justice' to refer to the branch of normative theorising according to which certain historical injustices demand reparation in the present. This makes reparative justice backwardlooking, in the sense that it seeks to ground contemporary normative claims and obligations in the actions and decisions of past generations.

Some claim there is a tension between a commitment to egalitarianism and support for reparative justice. In short, this tension seems to arise insofar as egalitarianism is a forwardlooking approach to justice: an approach that tells us what kind of world we should aim to build, where that world is not defined in terms of the decisions or actions of previous generations (see Butt 2009a, Ch.2). Egalitarians who nevertheless seek to defend obligations that are distinctly reparative in nature may appear to be confronted by something of a dilemma: either those obligations will overlap with the forward-looking demands of egalitarianism, in which case attention to history appears somewhat superfluous; or, they will conflict with the present-day demands of equality, in which case egalitarians should be sceptical of them after all. $^{2}$ The challenge for egalitarians who aim to defend reparation claims (including myself), ${ }^{3}$ is thus to account for the independent force of reparative justice without engendering a problematic conflict with their forward-looking egalitarian commitments.

Alasia Nuti terms this challenge the "redundancy objection"; the objection that a strong commitment to present-focused principles of egalitarian justice renders claims for reparations uncompelling $(2019,17) .{ }^{4}$ I will instead refer to it as the redundancy thesis, since egalitarians who do not seek to defend reparations may be quite content to accept or defend it. For egalitarians who do aim to show that reparations are not redundant, one seemingly appealing response is to say that historical injustices ground contemporary reparative obligations insofar as they have caused present-day inequalities (the causal approach). A promising alternative, skilfully defended by Nuti in Injustice and the Reproduction of History, is to argue that historical injustices demand reparation when they are reproduced into the present-day, such that some past and present injustices are in fact "the same injustice" (2019, 45). Both approaches may appear to have the potential to explain the necessity of reparations, without engendering a problematic conflict with the forward-looking demands of egalitarianism.

In this paper, I assess these two egalitarian responses to the redundancy thesis. I start by explaining the thesis more fully $(\S 2)$, before looking at the causal response and some

\footnotetext{
${ }^{1}$ See e.g. Manjapra 2018; Olusoga 2018; UCL 2021.

2 See Wenar 2006, 402.

${ }^{3}$ See Blomfield 2019, Ch. 10.

4 The idea that egalitarian justice would render reparative demands 'redundant' is also noted by Espindola and Vaca $(2014,230), \mathrm{Lu}(2017,175)$, Tan $(2007,302)$ and Valls $(2018,34)$.
} 
challenges that have been posed to it ( $§ 3)$. I then outline Nuti's alternative ( $\$ 4)$, before arguing that her response is confronted by the same challenges as the causal approach (§5). I find that Nuti's approach is ultimately equipped to succeed despite these challenges, with Nuti identifying several different ways in which egalitarians can take historical injustice to alter our present-day normative obligations. However, I show that similar lines of defence can be adopted by proponents of the causal approach (\$6). This appears to leave open the question of which approach should be preferred. In the closing section, I suggest that neither approach should be considered to provide an altogether superior way of conceptualising the relationship between historical injustice and our contemporary circumstances. Instead, our choice of approach should be determined by the historical injustice in question and our legitimate purposes in examining and discussing it (\$7).

The discussion in this paper proceeds at a fairly abstract level, talking of egalitarianism, reparations, and historical injustice in a general sense, and rarely getting into the specifics of such theories, claims, or injustices. This is because I am concerned, not with the question whether those who adopt a particular theory of egalitarianism can consistently support a certain method of reparation for a specific historical injustice; but rather with whether there is some form that egalitarianism can take, that would leave room for reparative justice to do independent normative work. I understand egalitarianism to be defined by a central claim that justice demands the creation of a world that is more equal in certain respects - where such equality might be understood in distributive terms, or relational terms. ${ }^{5}$ The forms that reparations may take are as varied as the many historical injustices that our world has been characterised by, and those who are not owed such reparation cannot determine what it must consist in.

\section{The Redundancy Thesis}

World history is replete with injustice. An important task for any theorist of historical injustice is thus to explain which past injustices possess contemporary normative significance; by explaining when - and why - historical injustice makes a difference to how we ought to evaluate, and respond to, our contemporary circumstances.

It has sometimes been suggested that egalitarians face a peculiar challenge when it comes to this task; one that makes it difficult for them to defend reparations for historical injustice. ${ }^{6}$ As explained in the introduction, this challenge appears to arise insofar as egalitarianism is understood as a forward-looking approach to justice. This is not to characterise egalitarianism as a theory that demands the achievement and maintenance of a specific patterned distribution of goods; or even a purely distributive theory at all. Egalitarians may instead be concerned with equality of relationships or status, and need not object to various distributive inequalities that arise when individuals, who start off on reasonably equal terms, make different choices against a background of fair social institutions. ${ }^{7}$ However, egalitarians are often sceptical of the idea

\footnotetext{
${ }^{5}$ On this distinction, see e.g. Arneson 2013.

${ }^{6}$ This challenge is discussed at length by Butt (2009a, Ch.2) and Tan (2007). For an account of how the mainstream liberal philosophy literature developed in such a way that "egalitarianism in theory was bought at the cost of ignoring historical and structural injustice in practice", see Forrester $(2019,50)$.

${ }^{7}$ Responsibility-sensitive egalitarians take (at least some) inequalities to be justified when they result from the responsible choices of individuals (see e.g. Knight 2013). The attention to past choice may appear to make this a backward-looking approach. However, it counts as forward-looking under the terminology that I adopt here, according to which backward-looking approaches permit the choices of past generations to play such a role.
} 
that individuals can justifiably inherit significant inequalities, or special rights and duties, from previous generations. In opposition to backward-looking theories of distributive justice - such as Robert Nozick's historical entitlement theory (1974) - egalitarians are likely to insist that the actions of past generations (such as their acquisitions and transfers) make no difference to the kind of world that we ought to pursue going forwards.

Egalitarianism thereby possesses resources for criticizing the accumulation of inequalities over time. However, this critique may appear to cut both ways, proscribing not only the inheritance of any inegalitarian advantages that have been generated in the past, but also the passing down of reparative duties. Insofar as egalitarians hold that each individual should start life with an equitable slate, it is unclear how the actions of previous generations (whether just or unjust) can make a significant difference to present-day entitlements and obligations (see Butt 2009a, 39-40). Egalitarians who seek to defend reparations are thus confronted by the redundancy thesis: the thesis, roughly speaking, that egalitarianism renders reparations for historical injustice redundant. This thesis is related to a long-discussed claim about the relationship between distributive and corrective justice, which Andrew Cohen formalises (in order to criticise) as follows $(2016,665)$ :

The normative irrelevance thesis: For any such true statement $\mathrm{P}$ [those with the form ' $\mathrm{X}$ has a claim that $\mathrm{Y}$ perform action $\Phi$ ', and those with the form ' $\mathrm{Y}$ has a duty to $\mathrm{X}$ to perform some action $\Phi^{\prime}$ '], appeals to distributive justice considerations, along with some relevant statements of fact, are sufficient to establish P. Distributive justice overdetermines corrective justice. Corrective justice then has no unique normative work to do.

Adapting Cohen's definition, what I am terming the redundancy thesis can be similarly formalised as:

The redundancy thesis: For any true statement (Q) concerning our present-day claims and obligations of justice, appeals to forward-looking egalitarian justice considerations, along with some relevant statements of fact, are sufficient to establish Q. Forwardlooking egalitarian justice overdetermines reparative justice. Reparative justice then has no independent normative work to do.

Egalitarians who aim to show that reparative justice does independent normative work must therefore find a way to reject the redundancy thesis. And in doing so, it seems that they must also explain why this will not result in a problematic conflict with their egalitarian commitments. The problem, according to Leif Wenar, is that if reparative principles are taken to have independent force, then they may counteract forward-looking principles of justice. For example, if egalitarians succeeded in bringing about a world where "blacks and whites were now perfectly equal in wealth, power, and prospects", Wenar suggests that reparations for slavery "would require us to dislodge this distribution of perfect justice, so that the world would become distributively less just". ${ }^{8}$ In fact, he claims, in a world like our own but where white

\footnotetext{
${ }^{8}$ As Wenar appears to acknowledge, this is an analog of Nozick's claim that liberty upsets patterns (Nozick 1974, 160ff.). In Wenar's case, however, it is reparations that are claimed to upset distributively just patterns of holdings. Furthermore, whilst Nozick takes his purported conflict to count against patterned theories of justice, Wenar takes it to count against reparative obligations.
} 
people now happened to be worse-off than black people, reparations for slavery might "require that these worst-off white citizens be made still worse off, so as to better the situation of betteroff blacks". ${ }^{9}$ Wenar suggests that most egalitarians will be resistant to the idea that justice might demand such a thing, and that this constitutes "proof" that reparative claims lack independent force, "separate from their overlap with principles of just distribution" (2009, 402).

Wenar's concern about the potential for conflict should not be overstated. Conflicting demands are not unusual in theories of justice and will be familiar to the many egalitarians who are not value monists. Priority rules offer one obvious way to deal with them. Bernard Boxill, for example, appears to think that rights to reparation place sideconstraints on the pursuit of equality. ${ }^{10}$ Theorists who are concerned about any antiegalitarian implications of this approach may instead follow Andrew Valls, who suggests that in cases of conflict, there are strong reasons to prioritise egalitarian principles (2018, 33; see also Tan 2007, 290-1). It may yet seem an undesirable result, however, if all reparation claims with independent force either constrain, or are overruled in favour of, the forward-looking pursuit of equality. In $\S 6$ I argue that fortunately, this is not an outcome that egalitarians are forced to accept.

Whilst I think it is important to attempt to understand the redundancy thesis - and the challenge that many believe it poses to an egalitarian defence of reparations - I also do not want to grant it more merit than it deserves. There are many ways of being an egalitarian, and the proponent of the redundancy thesis faces a daunting task if their aim is to show that all of them render reparation claims normatively irrelevant. I therefore expect that there are various ways in which egalitarians might seek to reject this thesis. In this paper I engage in a critical comparison of just two potential responses: the causal approach, and the detemporalisation approach that Nuti puts forward as a superior alternative.

\section{The Causal Response and some Challenges}

One way in which egalitarians might seek to reject the redundancy thesis is by adopting the "causalistic" (Nuti 2019, 48) or 'causal' approach. According to this approach, historical injustices give rise to contemporary reparative obligations when they are causally connected to, or have a continuing legacy of, inequality in the present. Proponents may argue that slavery, for example, gives rise to reparative obligations in the present due to the legacy of racial inequality that it has left behind; and that historical wrongs of colonialism engender contemporary normative demands due to their legacies of global inequality. Nuti lists Thomas McCarthy and Andrew Valls as advocates of this view (Nuti 2019, 17, fn. 13), another proponent of which appears to be Kok-Chor Tan (2007, §12.2). In Valls' words (2018, 119; emphasis added):

\footnotetext{
${ }^{9}$ See also Mulligan 2019, 847.

${ }^{10}$ In Boxill's words: "Some philosophers may protest that we should not allow claims for reparation to get in the way of an ideal egalitarian society, but of course their position is as bad as the utilitarian arguments they disparage that rights may and should be violated in order to maximize utility" $(2016, \S 6)$.
} 
the case for reparations, understood as public policies that aim to address racial inequality because of its roots in historic injustice, relies on the observation, supported by voluminous evidence, that present-day inequality is the result of past injustice. ${ }^{11}$

Such accounts might at first seem promising in that they appear to show how historical injustices can engender significant reparative demands in the present (grounding obligations to redress various inequalities), whilst avoiding Wenar's concern about conflicting duties. Here, "it is precisely because we aim to solve a normatively problematic [present] condition that we need to repair the past" (Nuti 2019, 17); and if both reparative and forward-looking egalitarian justice aim to redress problematic present inequalities, then it seems that their demands will coincide.

Unfortunately, however, this overlap of duties removes the conflict concern at the seeming expense of the redundancy thesis returning to the fore. If redressing inequalities is a forwardlooking demand of egalitarian justice, some will question what is gained by saying that it is also a reparative duty. As Tan acknowledges, it may once again seem that "arguments from reparations are superfluous [because] arguments from equality can do all the justificatory work" $(2007,281) .^{12}$ Even if contemporary racial inequalities, for example, are the legacy of past injustices, the proponent of the redundancy thesis can claim that this does not "normatively matter", because those inequalities demand redress according to our forward-looking egalitarian principles (Nuti 2019, 18-19). They might then question whether reparation claims have any independent force after all. Perhaps any intuitive appeal of such claims derives entirely from our conviction that present-day inequalities are unjust; and if forward-looking egalitarians were to succeed in their aims of creating a more equal world, "the unjust past would lose its significance" (Nuti 2019, 17). ${ }^{13}$

Another way to put this challenge would be that the causal approach has only succeeded in demonstrating that historical injustice possesses contemporary causal significance, in the sense that it enables us to explain why certain unjust inequalities have arisen. Attention to historical injustice may also thereby play an epistemic role: enabling us to discover present-day inequalities that we would otherwise have overlooked, to recognise patterns of wrongdoing that should not be repeated, and to better identify and understand barriers to the pursuit of equality (such as prejudice or mistrust). However, as Tan again acknowledges: even if our best causal explanations of current global inequality, for example, reference the colonial past; if those inequalities are unjust on forward-looking egalitarian grounds, then this causal history may appear "normatively irrelevant" in the sense that it is unnecessary for justifying a duty to redress those inequalities $(2007,285) .{ }^{14}$

In reply to the redundancy thesis, proponents of the causal approach might argue that egalitarians will sometimes have strategic reasons to defend reparation claims; for example, when debating libertarian theorists who deny the injustice of present-day inequalities. ${ }^{15}$ Some

\footnotetext{
${ }^{11}$ See also McCarthy 2004, 752-3, 758 .

12 This concern is also noted by Valls $(2018,34)$; who locates a similar worry in a 2001 statement by Human Rights Watch. See also Spinner-Halev 2012, 40; Vernon 2003, 548, 554.

13 See also Howard-Hassman 2011, 12; Lu 2005, 407; Shelby 2004, 1711-1712; 2011, 396; Vernon 2003, 552; Wenar 2006, 401-2. Some might claim that this is a situation in which the original injustice has been "superseded" (Waldron 1992).

${ }^{14}$ In Lyons' words: the claims of "subjugated descendants" may be causally rooted in the wrongs that their ancestors suffered, without being normatively derived from them $(1977,267)$.

${ }^{15}$ See Butt 2009a, 14-15; Collste 2014, 180; Mills 2019, 115-6; Tan 2007, 289, fn.20; Human Rights Watch 2001.
} 
have questioned this strategy. Worries may include that it lends support to an inegalitarian, historical entitlement theory of justice ${ }^{16}$; or that it will undermine efforts to address current inequalities by breeding division and resentment (Balfour 2014, 44), weakening the claim that current inequalities matter for their own sake (Shelby 2011,396), and leading those who are disadvantaged in ways that do not derive from historical injustice to be overlooked (O'Neill 1987, 87). However, more pertinent to the discussion at hand, some would argue that even if egalitarians sometimes have strategic reasons to defend reparations claims, this does not serve to prove that such claims have any genuine normative force of their own. As Wenar puts it, it might still appear that strategic reparative arguments "draw their force explicitly from [egalitarian] distributive concerns" $(2006,402) .{ }^{17}$

Egalitarians who adopt the causal approach can thus endow historical injustices with contemporary causal, epistemic, and (perhaps) strategic relevance. However, proponents of the redundancy thesis may continue to argue that reparative justice remains normatively superfluous on this approach; in the sense that historical injustice makes no real difference to how we ought to respond to the inequalities that characterise our contemporary circumstances. In §6 I argue that proponents of the causal approach can succeed in rejecting the redundancy thesis despite these challenges. But first, I explain and assess the alternative approach offered by Nuti.

\section{Nuti's Alternative: De-temporalisation}

For reasons such as those outlined in the previous section, though Nuti does not go so far as to claim that the causal approach is incapable of undermining the redundancy thesis, she does conclude that "as they stand, accounts focusing on the necessity of repairing the unjust past because of its effects on present inequalities do not offer an interpretation of the relation between past and present injustices that is sufficiently compelling" to reject it $(2019,19)$.

In her 2019 book, Nuti aims to develop an egalitarian theory of historical injustice that will prove more successful on this front. In short, she does this by collapsing the distinction between forward- and backward-looking theories of justice; challenging "the theoretical and normative divide between past and present injustice" via the idea of "de-temporalisation" (Nuti 2019, 9). In de-temporalising injustice, one refuses to separate certain past and present injustices from one another; instead conceiving them as the same injustice, which began in the past but has been reproduced over time, in different ways, into the very "fabric" of our societies and the international order (Nuti 2019, 178). When it comes to such injustices, Nuti claims, it would be an error to view them as truly past. Instead, we must recognise that the unjust past can sometimes be present "in a deep and dynamic way" (Nuti 2019, 13). The unjust past may be deeply present in the way that it shapes the background conditions of our lives, against which we interact with and relate to one another; and it will be dynamically present insofar as contemporary agents enable its reproduction through their actions and omissions (Nuti 2019, 4).

Nuti's de-temporalisation approach can be further illustrated by comparing it with the causal alternative. Referring to Walter Benjamin's image of the angel of history, Nuti suggests that in many cases "one has to look at historical and present injustices as a 'single catastrophe'

\footnotetext{
${ }^{16}$ See the discussion of this concern in Forrester 2019, 39-40.

${ }^{17}$ See also Nuti 2019, 18.
} 
rather than as a "chain of events" $(2019,45)$. For example, instead of viewing slavery in the US and police brutality against African American people as merely related to one another in a cause-effect relationship; the de-temporalisation approach suggests that we understand them as "the same injustice reproduced over time through changes and in new ways" (Nuti 2019, 160).

This de-temporalising move is made possible by Nuti's structural understanding of injustice, which conceptualises injustices not only as "singular events with a clear beginning and a putative end" (2019, 25); but also (and especially) as "long-term structures which endure over time and through generations". Nuti refers to such enduring cases as "historical-structuralinjustices" (HSIs), defined more precisely as $(2019,44)$ :

unjust social-structural processes enabling asymmetries between differently positioned persons, which started in the past and are reproduced in a different fashion, even if the original form of injustice may appear to have ended.

To illustrate this using the example with which this paper opened, of British involvement in Transatlantic slavery: Nuti would resist the idea that this historical injustice should be viewed as an event that spanned a particular period of time (starting sometime in the 1500s, say, and ending in 1834). Beyond concerns about the accuracy of such dates, this would be to overlook the fact that as a historical phenomenon, slavery "was also characterised by long-term structures that constituted its possibility of existence and that may have outlived the end of the 'event' of slavery" (Nuti 2019, 25-27). ${ }^{18}$ The long-term structures established by slavery such as racial hierarchies and stereotypes, psychological oppression, and economic, political and cultural disempowerment - may well outlast formal abolition and be reproduced into the present day. These long-term structures would then become the background conditions against which contemporary events - such as police brutality against black people - can occur. Nuti suggests that we should view this as a situation in which historical injustice remains deeply present through long-term structures, continuing to enable asymmetries between differently positioned persons, with contemporary agents helping to reproduce such injustice through their own actions and omissions.

Nuti argues that when it comes to HSIs, proponents of the redundancy thesis can no longer claim "that we have in the present all the normative resources to assess and address contemporary injustices" (2019, 21-22). If egalitarians aim to overcome the contemporary injustice of racist police brutality, for instance, then they will have to tackle the unjust past that, remaining present, creates the background conditions against which such injustice is possible. For example, by dissolving "the stereotypical association of blackness with criminality" that stems from the era of slavery. Nuti claims that the unjust past that remains structurally present in these cases "cannot be superseded by present-based considerations of justice, because... its new reproduction... deeply undermines the workings of contemporary institutions" - and may also challenge the very desirability of those institutions in the first place. With unjust history continuing to shape the "contours of our social reality" in this way, the realisation of egalitarian ideals such as non-discrimination is jeopardised, and the enforcement of formal egalitarian legislation will not translate into the achievement of substantive egalitarian goals (Nuti 2019, 48-50).

Nuti believes that her theory rebuts the redundancy thesis more successfully than the causal approach, establishing a "more compelling relation between unjust past and present", and

${ }^{18}$ Nuti is actually discussing slavery in the US here, but this reasoning will also apply to the British case. 
providing a "more nuanced explanation of why we cannot overlook an unjust history when we endorse equality in the present" $(2019,48)$. By collapsing the distinction between past and present injustices, it might appear that Nuti both removes the risk that the measures needed to repair the former will conflict with the policies required to address the latter; and undermines the view that egalitarians ought to take a purely forward-looking approach to justice in the first place. In the following two sections, however, I question whether Nuti's attempt to reject the redundancy thesis is actually more successful. I argue that in fact, it appears vulnerable to the same challenge faced by the causal response - namely, that it only succeeds in demonstrating that historical injustices possess contemporary causal or epistemic, rather than normative, significance. I also argue that whilst Nuti's approach is equipped to succeed despite this challenge, her lines of reply to the redundancy thesis can also be deployed by proponents of the causal alternative. In $\S 7$, I suggest that neither approach should be viewed as ultimately superior to the other. Instead, both should be considered as potential ways to conceptualise the relationship between historical injustice and our contemporary normative circumstances, either of which may be more or less appropriate depending on the historical injustice in question and our legitimate purposes in examining and discussing it.

\section{Assessing the De-temporalisation Response}

In this section I show that the challenges confronting the causal response to the redundancy thesis (identified in §3) are also faced by Nuti's alternative. The problem, in brief, is that Nuti's approach likewise suggests an overlap between the demands of reparative justice and her forward-looking theory, thereby raising the question whether the former have any independent force. Once again, the proponent of the redundancy thesis can argue that whilst Nuti may have succeeded in endowing historical injustices with causal (and perhaps epistemic) significance; she has not yet shown that they make any difference to how we ought to respond to our contemporary circumstances.

In more detail: on Nuti's approach, the historical injustices that demand contemporary redress are those that are reproduced into the present as enduring structural injustices that enable asymmetries between differently positioned persons. A familiar line of critique immediately appears available to the proponent of the redundancy thesis here, because insofar as these present-day asymmetries are ones that are intuitively objectionable, one might think that they demand remedy regardless of whether the structural injustice that they result from is historical in Nuti's sense. ${ }^{19}$ Arguments from reparations may thus once again seem superfluous and yet to be demonstrated as possessing any independent force. One may then suspect that if we were to succeed in removing such problematic asymmetries via forward-looking egalitarian efforts to redress contemporary structural injustice, the unjust past would (as Nuti puts it in her critique of the causal approach) "lose its significance" $(2019,17)$.

Having presented this as a challenge to the causal approach herself, Nuti is alert to this problem and does aim to show that her account overcomes it. She provides several examples that are supposed to illustrate how purely forward-looking efforts to confront structural injustice cannot succeed when it comes to HSIs. The core case she relies on, in the section of the book concerning how her approach does not render historical injustice redundant (§3.3),

\footnotetext{
${ }^{19}$ Nuti in fact acknowledges that demands for reparations may overlap in content with the "demands of present distributive and structural injustice" $(2019,164)$.
} 
is the systematic shooting of African American men by the police. By significantly shaping our social reality, Nuti claims, the unjust past creates the background conditions that structure and enable these violent wrongs. Viewing this as an instance of HSI thus allows us to interpret this phenomenon not merely as a series of wrongs committed by individual perpetrators, but also as an injustice that is made possible by "the structural reproduction of an unjust history". Without this perspective, she claims, "we can neither understand how certain wrongs are also injustices nor capture the full injury such injustices inflict" (Nuti 2019, 48-9).

However, proponents of the redundancy thesis again seem able to push back here. Surely, they might claim, even purely forward-looking egalitarians can deem such systematic, statesponsored violence an injustice, independent of "the historical-structural processes behind daily racial interactions and relations in the US" (Nuti 2019, 48). Forward-looking egalitarians can agree with Nuti that "If we aim to overcome contemporary grave injustices" such as police violence against black people, then we must tackle the background structural conditions that make such injustice possible (2019, 49-50; emphasis added). But they may argue that in doing so, we need not treat historical injustice as making a difference to our obligations. Even when historical injustice underlies the background conditions of this 'contemporary grave injustice', surely we should be able to deem those conditions objectionable from a purely forward-looking egalitarian perspective: for example because they are prejudicial or oppressive; or because they enable the grave injustice of racist police brutality.

As explained in the previous section, Nuti does also claim that the unjust past "cannot be superseded by present-based considerations of justice, because... its new reproduction... deeply undermines the workings of" - and challenges the very desirability of - "contemporary institutions". By shaping the "contours of our social reality", the unjust past can jeopardise egalitarian ideals and prevent formal egalitarian legislation from translating into the achievement of substantive egalitarian goals (Nuti 2019, 48-50). However, the proponent of the redundancy thesis might again argue that Nuti has at best shown that historical injustice has causally contributed to society being structured in these ways. Attention to historical injustice may thereby play an epistemic role, enabling us to discover present-day structural injustices that we would otherwise have overlooked, to recognise patterns of wrongdoing that should not be repeated, and to better identify and understand barriers to the pursuit of egalitarian justice (such as the norms, scripts, stereotypes, formal or informal institutions, and other problematic background conditions that Nuti rightfully highlights). However, if these seemingly benign structures or institutions are, on closer inspection, acting as a barrier to our efforts to build a more equal society; then it seems that purely forward-looking egalitarians can defend duties to address them after all. Similarly, forward-looking egalitarians can accept Nuti's claim that they are unlikely to be able to achieve their goals through the mere enforcement of formal egalitarian legislation, in the presence of background structural conditions that undermine the operation of egalitarian institutions. But again, though history may be causally relevant in the sense that is has produced those background conditions; the fact that those conditions are now undermining the realisation of egalitarian goals seems sufficient to ground a forwardlooking egalitarian obligation to address them.

Thus, similar to the causal account, Nuti appears vulnerable to the objection that her approach has only succeeded in demonstrating that historical injustice possesses contemporary causal or epistemic significance, in the sense that it enables us to explain and understand how certain structural injustices have arisen. But insofar as the structural asymmetries of the present can be deemed unjust on forward-looking egalitarian grounds, they appear to demand remedy independent of that history. That is, whilst we may need to attend to history to explain the 
existence (and persistence) of present-day structures that constitute an injustice, we do not need to attend to history in order to recognise such structures as unjust, and in need of redress. ${ }^{20}$ The proponent of the redundancy thesis may thus again insist that for egalitarians such as Nuti, historical injustice remains normatively irrelevant in the sense that it makes no difference to how we ought to respond to the inequalities, or structural asymmetries, that characterise our contemporary circumstances.

A more promising response to the redundancy thesis is offered by Nuti's claim that "although a society may appear just from a present-based perspective of justice, it may turn out to be unjust when a historical-structural outlook is endorsed" $(2019,50)$. If Nuti can demonstrate that there are some contemporary circumstances that can only be recognised as unjust due to their relationship with historical wrongdoing, then she would be in a position to argue that the redress of such injustices is demanded on distinctly reparative - rather than forward-looking egalitarian - grounds. The problem, however, is that I do not think Nuti provides an example that would convince proponents of the redundancy thesis to accept this claim.

To support this claim, Nuti needs to provide an example of a way in which society can be judged unjust from a historical but not a present-based perspective. However, if her example refers to a present-day situation that is clearly objectionable, any egalitarian worth their salt will be reluctant to accept that we might not deem it an injustice were we not aware of its history. For example, egalitarians will rightly refuse to accept that a society in which African American women experience systematic infringement of their reproductive rights, ${ }^{21}$ and African American men experience systematic violence at the hands of the police, can only be recognised as unjust, and thus in need of redress, once we understand the history that lies behind these phenomena. In order to respond to the redundancy thesis, we therefore need a clearer answer to the question of how historical injustice may be normatively, and not just causally, relevant to our present-day pursuit of justice.

Nuti's approach does, however, appear equipped to provide such an answer. First, Nuti could present an example that more clearly demonstrates how a historical-structural perspective may be necessary for recognising a society to be unjust in certain ways. If Nuti can identify a case in which attention to historical injustice will lead us to judge that an aspect of society is unjust and in need of redress, though it would not be judged so on purely forwardlooking egalitarian grounds, then she will have succeeded in identifying a case in which redress is an independent demand of reparative justice. In the next section, I will say more about how it should be possible to identify such cases.

Furthermore, however, Nuti is clear that her existing examples serve an additional purpose. Whether or not these cases can be deemed unjust on forward-looking egalitarian grounds, she also claims that it is not possible to grasp their "full injury" from this perspective: an injury that "precisely consists in the ongoing reproduction over time of the same injustice" $(2019,51)$. If the injury of contemporary injustices is more significant when they are related to historical injustices in the right way, then the demand to redress such injustices will presumably be weightier - with this difference arising on the basis of reparative, rather than forward-looking, justice. Third, and relatedly, Nuti also argues that a purely forward-looking approach cannot comprehend how HSIs ought to be redressed, and the specific claims for reparation that those experiencing them hold against particular agents (Nuti 2019, 63). Once again, then, reparative

${ }^{20} \mathrm{I}$ am grateful to an anonymous reviewer for suggesting this way of phrasing things.

${ }^{21}$ A case that Nuti discusses in Chapter 8. 
justice may do independent normative work by demanding that when contemporary injustices are related to historical ones in the right way, present-day redress must take a different form and come from a different source - than it otherwise would.

Nuti therefore highlights three lines of response by which egalitarians may seek to reject the redundancy thesis; thus also providing a more detailed account of some of the different ways in which historical injustices may be seen to alter our present-day normative claims and obligations. In the next section I attempt to further illustrate how these lines of response may be developed. However, I do so by showing how they can in fact be deployed by proponents of the causal approach. I conclude that whilst Nuti's account does appear equipped to respond to the redundancy thesis, she is wrong to suggest that her response is superior to that which can be offered by the causal approach.

\section{Supporting the Causal Response}

Similar to Nuti, proponents of the causal approach can seek to reject the redundancy thesis by showing how legacies of historical injustice may lead us to judge that society is unjust, and thus in need of redress, though it would not be judged so on purely forward-looking egalitarian grounds (see Tan 2007, 289). An obligation to redress such legacies would thus be an independent demand of reparative justice.

Wenar's worry about conflict may, however, appear to arise here $(2009,402)$. If reparative justice is taken to ground obligations that diverge from the forward-looking demands of egalitarianism, should we not be concerned about inconsistency? As explained in $\$ 2$, one way to deal with such conflict is to state that the demands of equality should always be given priority. However, I take it that an egalitarian defence of reparative justice will be somewhat empty if all reparative obligations with independent force are subsequently overruled by principles of egalitarian justice. Another option would be to follow Bernard Boxill in insisting that - in some cases at least - rights to reparation should place side-constraints on the pursuit of equality $(2016$, §6). Some egalitarians may, however, be reluctant to accept such constraints.

Fortunately, another option open to proponents of the causal approach is to point out that the potential for conflict is overstated by Wenar, neglecting the fact that there can be significant room for manoeuvre within the bounds of egalitarian justice. ${ }^{22}$ Egalitarians need not be concerned with every kind of inequality, and the kind of equality that their forwardlooking theory deems to be of importance may well be compatible with inequalities in many other dimensions. Equality of opportunity, for example, might be achieved despite various inequalities in other goods; and relational equality might be compatible with different distributions of material resources. A plausible egalitarianism will not fully specify what a just world looks like, then, but will instead set certain parameters within which an egalitarian world might be realised in different ways.

Historical injustice may entail that we ought to pursue some worlds within this set rather than others, by giving rise to inequalities (or asymmetries) that would not necessarily violate

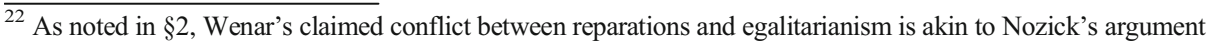
that liberty will inevitably undermine 'patterned' theories of justice. Simmons accuses Nozick of mistakenly treating patterned theories "as if their favored principles were intended to govern all distributions of goods within societies" (Simmons 1995, 161, fn.20; emphasis added). I am here claiming that Wenar makes a similar mistake, by suggesting that egalitarian theories (and distributive theories of justice more generally) will uniquely determine the distribution of all goods.
} 
the demands of egalitarianism if they had arisen in a fair way, but do violate the demands of justice insofar as they are the result of wrongdoing. Wenar thus appears to present a false dilemma (relying on an implausible picture of egalitarianism) when he suggests that we are forced to accept: either that principles of reparative justice have no independent force; or that they will demand that we depart from a perfect instantiation of egalitarian justice $(2006,402)$. Instead, reparative principles could possess independent force in the sense that they require us to pursue one instantiation of forward-looking egalitarian justice rather than another. Take, for example, the claim that reparations for slavery should include a right of repatriation to Africa for the descendants of those who were enslaved. ${ }^{23}$ Such claims may well be distinct from (because not demanded by) but compatible with (because not ruled out by) many forms of forward-looking egalitarianism. There may also be various distributions of the world's artefacts, land, or money, say, that are compatible with one's forward-looking theory of egalitarian justice; but insofar as the existing distribution is a result of theft rather than gift, attention to historical injustice might mean that justice now demands the achievement of some of these distributions rather than others.

More generally speaking, if forward-looking egalitarian principles only set parameters on what a fair state of affairs will look like, then they will permit other considerations - including historical considerations - to have bearing on which states of affairs ought to be pursued in the present. It is plausible, that is, that several different states of affairs would satisfy the demands of forward-looking egalitarianism and that in choosing between them, we should aim for the one in which individuals and groups have access to goods that hold particular historical significance for them - especially due to reasons of historical injustice. Similar to Nuti, then, proponents of the causal response can attempt to show that even if society appears just from a present-based perspective, it may turn out to be unjust and in need of redress once one recognises that some otherwise untroubling inequalities are a legacy of historical injustice.

Secondly, proponents of the causal approach can also argue that even when a present-day inequality does matter on grounds of forward-looking egalitarianism, it will matter in a different way insofar as it is also the product of historical injustice. Some insist that the overlap of reparative and egalitarian duties is a benefit rather than a weakness, because it makes such duties complementary. ${ }^{24}$ Following Nuti, one might further insist that this overlap does have real normative significance, because it changes the nature of the injustices that characterise the present and the injury that they inflict. It may simply make a significant normative difference whether present-day inequalities that are unjust on grounds of forward-looking egalitarianism (racial inequalities, say) do or do not also derive from historical injustice (such as slavery). ${ }^{25}$ One might think that when they do, the injury that they inflict is more significant, and our duties to remedy the present inequality should be understood as weightier. ${ }^{26}$ This would appear to entail that if forced to choose between remedying one inequality or another, you should remedy the inequality that is the product of historical injustice, rather than the inequality that only results from contemporary factors - at least when other things are equal (see Butt 2009b, 179-80), but perhaps even in cases where they are not. The obligation to

\footnotetext{
${ }^{23}$ See e.g. CARICOM 2021.

24 See Collste 2014, 15-16; Tan 2007, 291; Valls 2018, 33.

25 In Platz and Reidy's words: "Something is lost if we treat the asymmetric distribution of harms from past injustices as if they were not different from an asymmetric distribution of harms worked through the forces of nature or imposed by God" $(2006,372)$.

${ }^{26}$ See also Young 2011, 182.
} 
prioritise such injustices is not something that can be derived from forward-looking egalitarian principles alone, thus undermining the redundancy thesis.

And thirdly, proponents of the causal approach can also argue that historical injustice may alter the means by which current unjust inequalities should be redressed. For example, it is often thought that reparation of historical injustice must have a symbolic or expressive dimension; meaning that current inequalities can only be redressed in a way that serves both forward-looking egalitarianism and reparative justice if redistribution is accompanied by symbolic measures. ${ }^{27}$ It may also be necessary for redress to take place under a particular description - characterized by particular motivations - if it is to satisfy the demands of both forward-looking egalitarianism and reparative justice (Mills 2019, 116-117; Valls 2018, 119). If the present-day redress of racial inequality is to serve as reparation for the injustice of slavery, then, it will have to be accompanied by certain symbolic measures and motivations, even if the more material aspects of redress remain the same.

More generally speaking, even if the end goals of reparative justice overlap with those of egalitarian justice, the fact of this overlap may mean that those goals must be pursued in a different way. ${ }^{28}$ If present unjust economic inequalities, for example, are not the result of past injustice, the correct remedy might be a general redistributive scheme into which the advantaged pay, and from which the disadvantaged receive. But if those inequalities are instead the result of particular historical injustices, rectification might demand transfers of resources between specific parties: for example, from Britain directly to Jamaica, or from descendants of slave owners to descendants of those who were enslaved, rather than via a general distributive mechanism. ${ }^{29}$ The need to include symbolic measures, or carefully design appropriate redistributive schemes, may make the redress of present-day inequalities far more demanding. But such demandingness can be justified by the normative status of such inequalities - as unjust on grounds of both forward-looking egalitarianism and connection to historical wrongdoing.

Let me summarise this section. In order to rebut the redundancy thesis, proponents of the causal approach can insist that when present-day inequalities are the result of historical injustice, this may change their normative status and thereby entail: first, that those inequalities should be deemed unjust and in need of redress, even though they would not be judged so on purely forward-looking egalitarian grounds; second, that this enhances the injury inflicted by such inequalities, and may entail that their redress should be prioritized over that of inequalities that are only unjust on forward-looking egalitarian grounds; and third, that such redress must take a different form. These three lines of response are essentially those that Nuti identifies in her defence of the de-temporalisation approach. I therefore conclude that both approaches appear similarly equipped to reject the redundancy thesis.

\section{Which Approach Should we Adopt?}

If the causal and de-temporalisation approaches are similarly able to respond to the redundancy thesis, are there other reasons for judging one superior to the other? Here, Nuti might press her claim that causal accounts provide a relatively impoverished picture of the relationship

\footnotetext{
${ }^{27}$ See Cohen 2016; Tan 2007, 287-8; Mills 2013, 11; Valls 2018, 33-34.

${ }^{28}$ See also Matthew 2017, 246-7; Pierik 2006.

${ }^{29}$ See also Cohen 2016, 668-9.
} 
between historical injustice and our contemporary circumstances, invoking "a too direct link between past injustice and present inequalities" $(2019,28)$.

As Nuti argues, in thinking of past and present injustices as connected to one another in a straightforward cause-effect relationship, one may fail to attend to the way in which such relationships can be mediated by long-term structures that persist across time - even once the original injustice has supposedly ended (through, e.g., abolition, or the formal withdrawal of colonial rule). One may also thereby overlook the way in which those structures, and the injustices that they engender, are sustained by many forms of intervening agency. The causal approach may thus suggest that what reparative justice demands is the rectification of certain remaining "passive" effects, of injustices that were successfully brought to an end in the past (Nuti 2019, 194). The de-temporalisation approach, on the other hand, suggests that the problem is that of finding a way to end and redress an injustice that has been reproduced across time, often sustained by powerful agents that thereby continue to accumulate a significant reparative debt (Nuti 2019, 157-161).

We must therefore consider whether it is overly simplistic to describe the relationship between historical injustice and our contemporary circumstances in terms of cause and effect. But this is something that appears to be recognised by Valls and McCarthy; two theorists that Nuti identifies as proponents of the causal approach (Nuti 2019, 17, fn. 13). Valls, for example, in more recent work states that "The overrepresentation of African Americans among the less well off in American society reflects the persistence of an unjust past into the present... What matters most in the present context is that the prior regime created deep, structural inequality that continues to decisively shape individuals' life prospects" (2018, 41-42; emphases added). McCarthy, on the other hand, claims that $(2004,760)$ :

To establish the continuing responsibility of a nation to repair continuing harms due to past injustices, one need not - and in the case of injustices that lie far enough in the past, often cannot - draw a causal line directly from those past actions to present harms. A more complex narrative is called for - for instance, one in which the repeated refusal to acknowledge past wrongs and the continued failure to remedy them are themselves fresh wrongs that compound the original one, in which deep-seated racist attitudes are continually expressed in new and different ways, and in which hierarchies of power and privilege are continuously maintained in ever-changing circumstances.

That the same theorists talk in ways that sometimes seem to fit the causal picture, but other times evoke a de-temporalised approach, suggests to me that we might view these alternatives not as rivals, but rather as two potential options for conceptualising the relationship between historical injustices and our contemporary normative circumstances; either of which may be more or less appropriate depending on the historical injustice in question and our ends in examining and discussing it.

Recall the classic billiard ball example that is often used to illustrate the phenomenon of causation. Two people who agree about the material facts of this case may nevertheless conceptualise it in different but compatible ways: the first viewing it as one event [ball 1 hitting ball 2] causing another event [ball 2 falling into the pocket]; and the second thinking of it as a single event or process [ball 1 knocking ball 2 into the pocket]. When considering the relationship between historical injustice and our present circumstances, perhaps even those who agree about the material facts can be faced with a similar choice: about whether to 
conceptualise it as a situation in which a past injustice is causally connected to a present injustice; or as a single injustice that has been reproduced across time.

I do not have space to explore this idea in much depth, but one way to develop it would be to suggest that when seeking to analyse historical injustice and its relationship with our present normative circumstances, we should understand ourselves to be engaged in an ameliorative project; a project that is guided by, and designed to help us to achieve, our legitimate purposes (see Haslanger 2005, 11). Such a project may have various legitimate purposes. Identifying and defending reparative obligations would be one, but others might include: highlighting the achievements of those who have fought to overcome injustice; opposing those who wrongly insist that certain forms of injustice are resigned to the past; respecting and centring the perspectives of those who are on the receiving end of injustice ${ }^{30}$; tracing the contemporary effects of particular unjust events, laws and institutions; and accurately representing the processes and structures by which injustices, or their effects, may be sustained over time. Depending on our aims, the causal, de-temporalisation, or alternative approaches to conceptualising the relationship between historical injustice and our contemporary circumstances may be more or less appropriate.

For example, if one aims to investigate certain contemporary effects of British slaveownership as a particular and unique historical institution (e.g. by examining how the wealth resulting from this injustice has passed down family or company lines, or remains embodied in infrastructure and public monuments), ${ }^{31}$ then adopting a simple causal picture may be perfectly adequate - and would also enable you to state that there is a sense in which abolitionists did succeed in ending one significant form of injustice when slavery was formally abolished, even despite such ongoing legacies, and the continuance of other forms of racial injustice. If, on the other hand, your aim is to understand the long history of black oppression in Britain and the places that it has colonized - and the structures and agency that have sustained such oppression over time, despite formal changes in circumstances - then as explained above, the de-temporalisation approach promises to provide a more detailed account of this phenomenon; one which can emphasise how even after formal abolition, many of the oppressive structures that sustained or were established by the institution of slavery persisted (see Nuti 2019, 26). In the case of a complex historical injustice like slavery, then, perhaps either of these approaches may be adopted depending on our legitimate purposes.

In other cases, it may be that the injustice in question, and any legitimate purposes in seeking to conceptualise it, count in favour of one approach rather than the other. As Nuti points out, "the neat division between the past and the present" - which the causal picture appears to allow - can sometimes be "a dangerous illusion preserved to the advantage of a few" $(2019,12)$. Glen Coulthard gives reason to think that this is the case when it comes to the injustice of settler colonialism, arguing that $(2014,22,108-9)$ :

in settler-colonial contexts such as Canada - where there is no formal period marking an explicit transition from an authoritarian past to a democratic present - state-sanctioned approaches to reconciliation tend to ideologically fabricate such a transition by narrowly situating the abuses of settler colonization firmly in the past... In such conditions, reconciliation takes on a temporal character as the individual and collective process of

\footnotetext{
${ }^{30}$ Who may thereby have "a privileged standpoint on the workings of that injustice" (Nuti 2019, 18, fn. 17).

${ }^{31}$ See, for example, UCL 2021.
} 
overcoming the subsequent legacy of past abuse, not the abusive colonial structure itself. $^{32}$

Coulthard suggests that to avoid such problematic "conceptual revisionism", one should follow Patrick Wolfe in understanding the injustice of settler-colonialism not as an event ("which occurred at some relatively fixed period in history but which unfortunately continues to have negative consequences for our communities in the present"), but as a structure that continues to organise society in pursuit of colonial ends (Coulthard 2014, 108, 125). Coulthard thereby suggests that we have strong reasons to conceptualise this injustice more in line with a de-temporalisation approach.

I therefore propose that we view Nuti's approach and the causal alternative as two options that are available to us when considering the relationship between historical injustice and our contemporary circumstances; whilst remaining attentive to the possibility that our legitimate purposes may call for particular - or additional (cf. Dotson 2012) - ways of conceptualising this relationship.

\section{Conclusion}

Are reparations owed for historical injustices such as Transatlantic slavery? Egalitarians who aim to answer yes to this question are confronted by what I have termed the redundancy thesis: the thesis, roughly speaking, that forward-looking egalitarian justice overdetermines reparative justice and leaves it with no independent work to do. In this paper I have examined two means by which egalitarians may attempt to reject this thesis: the causal approach, and the detemporalisation approach that Nuti presents as a superior alternative. I found that both approaches in fact face similar challenges, but also possess similar resources for successfully rebutting the redundancy thesis. This appears to leave us with the question of which of the causal or de-temporalisation approaches we should adopt. In the closing section of this paper, I suggested that neither approach should be viewed as altogether superior to the other. Even when considering the same historical phenomena, we may sometimes have reason to conceptualise them as one injustice that has left behind a legacy of other injustices; but other times to conceptualise them as a single injustice that has been reproduced across time. In choosing between the causal and de-temporalisation (or other) approaches, then, we should be guided by the nature of the historical injustice in question, and our legitimate purposes in seeking to understand it.

Acknowledgments I am grateful to Alasia Nuti, Eric Olson and Fabian Schuppert for discussion of some of the ideas in this paper; and Chris Bertram, Tim Fowler, Jessica Begon, Stephanie Collins, Adam Slavny, Chris Mills and Tom Parr for feedback on a first draft. My thanks are also due to two anonymous reviewers for ETMP for their detailed comments and recommendations.

Open Access This article is licensed under a Creative Commons Attribution 4.0 International License, which permits use, sharing, adaptation, distribution and reproduction in any medium or format, as long as you give appropriate credit to the original author(s) and the source, provide a link to the Creative Commons licence, and indicate if changes were made. The images or other third party material in this article are included in the article's Creative Commons licence, unless indicated otherwise in a credit line to the material. If material is not included

32 See also Tsosie 2007, 45. 
in the article's Creative Commons licence and your intended use is not permitted by statutory regulation or exceeds the permitted use, you will need to obtain permission directly from the copyright holder. To view a copy of this licence, visit http://creativecommons.org/licenses/by/4.0/.

\section{References}

Arneson R (2013) Egalitarianism. In: Zalta E (ed) The Stanford encyclopedia of philosophy. https://plato. stanford.edu/archives/sum2013/entries/egalitarianism/. Accessed 3 June 2021

Balfour L (2014) Unthinking racial realism: a future for reparations? Du Bois Review 11(1):43-56

Blomfield M (2019) Global justice, natural resources, and climate change. Oxford University Press

Boxill B (2016) Black reparations. In: Zalta E (ed) The Stanford encyclopedia of philosophy. https://plato. stanford.edu/archives/sum2016/entries/black-reparations/. Accessed 3 June 2021

Butt D (2009a) Rectifying international injustice. Oxford University Press

Butt D (2009b) "Victors' justice"? Historic injustice and the legitimacy of international law. In: Meyer L (ed) Legitimacy, justice and public international law. Cambridge University Press, pp 163-185

CARICOM (2021) CARICOM Ten Point Plan for Reparatory Justice. https://caricom.org/caricom-ten-pointplan-for-reparatory-justice/. Accessed 3 June 2021

Cohen A (2016) Corrective vs. distributive justice: the case of apologies. Ethical Theory Moral Pract 19:663-677

Collste G (2014) Global Rectificatory justice. Palgrave Macmillan

Coulthard GS (2014) Red Skin, White Masks. University of Minnesota Press

Dotson K (2012) A cautionary tale: on limiting epistemic oppression. Front J Women Stud 33(1):24-47

Espindola J, Vaca M (2014) The problem of historical rectification for Rawlsian theory. Res Publica 20(3):227243

Forrester K (2019) Reparations, history and the origins of global justice. In: Bell D (ed) Empire, race and global justice. Cambridge University Press, pp 22-51

Haslanger S (2005) What are we talking about? The semantics and politics of social kinds. Hypatia 20(4):10-26

Howard-Hassman R (2011) Reparations to Africa. University of Pennsylvania Press

Human Rights Watch (2001) An Approach to Reparations. https://backend.hrw.org/news/2001/07/19/approachreparations. Accessed 1 July 2020

Knight C (2013) Luck Egalitarianism. Philos Compass 8(10):924-934

Lu C (2005) Cosmopolitan liberalism and the faces of injustice in international relations. Rev Int Stud 31(2):401408

Lu C (2017) Justice and reconciliation in world politics. Cambridge University Press

Lyons D (1977) The new Indian claims and original rights to land. Soc Theory Pract 4(3):249-272

Manjapra K (2018) When will Britain face up to its crimes against humanity? The Guardian, March $29^{\text {th }}$. https:// www.theguardian.com/news/2018/mar/29/slavery-abolition-compensation-when-will-britain-face-up-to-itscrimes-against-humanity. Accessed 5 March 2021

Matthew DC (2017) Rawls and racial justice. Polit Philos Econ 16(3):235-258

McCarthy T (2004) Coming to terms with our past, part II: on the morality and politics of reparations for slavery. Political Theory 30:623-648

Mills C (2013) Retrieving Rawls for racial justice? A critique of Tommie Shelby. Crit Philos Race 1(1):1-27

Mills C (2019) Race and global justice. In: Bell D (ed) Empire, race and global justice. Cambridge University Press, pp 94-119

Mulligan T (2019) Should current generations make reparation for slavery? Australas J Philos 97(4):847

Nozick R (1974) Anarchy, state, and utopia. Blackwell Publishing

Nuti A (2019) Injustice and the reproduction of history: structural inequalities, gender and redress. Cambridge University Press

O’Neill O (1987) Rights to compensation. Soc Philos Policy 5(1):72-87

Olusoga D (2018) The Treasury's tweet shows slavery is still misunderstood. The Guardian, February $12^{\text {th }}$. https:/www.theguardian.com/commentisfree/2018/feb/12/treasury-tweet-slavery-compensate-slave-owners. Accessed 2 March 2021

Pierik E (2006) Reparations for luck egalitarians. J Soc Philos 37(3):423-440

Platz J, Reidy D (2006) The structural diversity of historical injustices. J Soc Philos 37(3):360-376

Shelby T (2004) Race and social justice: Rawlsian considerations. Fordham Law Rev 72(5):1697-1714

Shelby T (2011) Reparations, leadership, and democracy; a comment on Balfour and Gooding-Williams. Du Bois Review 8(2):395-399

Simmons AJ (1995) Historical rights and fair shares. Law Philos 14:149-184

Spinner-Halev J (2012) Enduring injustice. Cambridge University Press 
Tan K-C (2007) Colonialism, reparations, and global justice. In: Miller J, Kumar R (eds) Reparations: interdisciplinary inquiries. Oxford University Press, pp 208-306

Tsosie R (2007) Acknowledging the past to heal the future: the role of reparations for native nations. In: Miller J, Kumar R (eds) Reparations: interdisciplinary inquiries. Oxford University Press, pp 43-68

UCL (2021) Legacies of British Slave-ownership; Context. https:/www.ucl.ac.uk/lbs/. Accessed 5 March 2021 Valls A (2018) Rethinking racial justice. Oxford University Press

Vernon R (2003) Against restitution. Polit Stud 51(3):542-557

Waldron J (1992) Superseding historic injustice. Ethics 103:4-28

Wenar L (2006) Reparations for the future. J Soc Philos 37(3):396-405

Young IM (2011) Responsibility for justice. Oxford University Press

Publisher's Note Springer Nature remains neutral with regard to jurisdictional claims in published maps and institutional affiliations. 